\title{
Recording of tinnitus psychoacoustic measurements: an integrative literature review
}

\author{
Laura Mochiatti Guijo ${ }^{1}$ \\ https://orcid.org/0000-0003-2351-1105 \\ Angela Renata Sarambelli Fonseca ${ }^{2}$ \\ https://orcid.org/0000-0003-0102-3899 \\ Mirella Boaglio Horiuti ${ }^{3}$ \\ https://orcid.org/0000-0001-9131-618X \\ Laura Garcia E. Vasconcelos ${ }^{4}$ \\ https://orcid.org/0000-0003-0461-8724 \\ Ana Claudia Vieira Cardoso 5 \\ https://orcid.org/0000-0001-6808-419X \\ Jeanne Oiticica ${ }^{4}$ \\ https://orcid.org/0000-0001-9150-3962
}

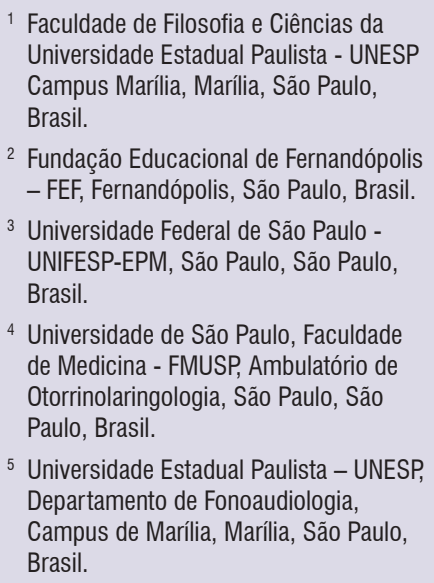
Universidade Estadual Paulista - UNESP Campus Marília, Marília, São Paulo, Brasil.

Fundação Educacional de Fernandópolis - FEF, Fernandópolis, São Paulo, Brasil. Universidade Federal de São Paulo UNIFESP-EPM, São Paulo, São Paulo, Brasil.

Universidade de São Paulo, Faculdade de Medicina - FMUSP, Ambulatório de Otorrinolaringologia, São Paulo, São Paulo, Brasil.

${ }^{5}$ Universidade Estadual Paulista - UNESP, Departamento de Fonoaudiologia, Campus de Marília, Marília, São Paulo, Brasil.

Conflict of interests: Nonexistent

\section{(c) (i)}

Received on: October 19, 2018

Accepted on: March 25, 2019

Corresponding address:

Laura Mochiatti Guijo

Rua Guiro Shimabukuro, $n^{0}$ 106, Bairro

Parque das Acácias

CEP: 17510-050 - Marília, São Paulo,

Brasil

E-mail: lauramochiatti@hotmail.com

\section{ABSTRACT}

Purpose: to review both the national and international literature as well as to describe the methods used to collect psychoacoustic measurements in tinnitus patients.

Methods: the current integrative review was conducted on articles in specialized national and international journals, in both the Portuguese and English languages, available in the PubMed/Medline, BVS - LILACS and SCIELO databases. The following keywords and descriptors were used: hearing, tinnitus, psychoacoustic measurements, acuphenometry, and assessment, in both the Portuguese and English languages. The retrieved articles were read and selected for the review according to the eligibility criteria, which included the use of psychoacoustic measurements in tinnitus patients and the presence of a detailed methodological description of the protocol employed, in individuals with normal hearing and those with hearing loss.

Results: a total of 12 articles, in which psychoacoustic measures were used for the characterization and the measurement of tinnitus in individuals with normal hearing and in those with hearing loss, were reviewed. The main findings were associated with the sample characterization and the way in which the psychoacoustic measures were performed.

Conclusion: given the grouping of several protocols for tinnitus evaluation, which were determined following an integrative literature review, a great heterogeneity in the methods used to perform psychoacoustic measurements for tinnitus assessment for both clinical and scientific purposes was noted.

Keywords: Hearing; Tinnitus; Hearing Loss; Psychoacoustics 


\section{INTRODUCTION}

Tinnitus has been previously described in the scientific literature as the perception of sound in the absence of an external environmental source ${ }^{1,2}$. More precisely, such a symptom may originate from an injury occurring at any point of the auditory pathway (i.e. outer ear, middle ear, inner ear, auditory nerve, cochlear nucleus, inferior colliculus, and/or the central nervous system) ${ }^{3}$. The literature ${ }^{4}$ reports that hearing loss, even when temporary, may cause an increase in the sensitivity of the neurons of the subcortical auditory centers, resulting in tinnitus.

While tinnitus may be present in individuals with normal hearing, the perception of such a symptom may vary in location, i.e. either in the ears or in the head 5 .

Although tinnitus is a well-recognized hearing impairment, a method considered as the "gold standard" for its characterization and measurement is yet to be defined. Generally, questionnaires are used to subjectively measure the discomfort and the impact of tinnitus in the patient's quality of life. An example is provided by the Tinnitus Handicap Inventory (THI), which was developed in $1996^{6}$ and exists in various versions in several languages, including Brazilian Portuguese ${ }^{7}$. Although one of the most common tools for tinnitus evaluation worldwide, questionnaire-based assessments are subjective and are not capable of measuring the magnitude of the patient's discomfort and the degree of disability caused by the symptom in an objective manner.

Similarly, acuphenometry is one of the oldest methods for evaluating tinnitus and is still widely used. In fact, it can define the frequency (pitch) and intensity (loudness) of the tinnitus, as well as the minimum masking levels ${ }^{8}$ (MML) and the residual inhibition", which are internationally known as the psychoacoustic measures.

One of the first acuphenometry records dates to $1931^{10}$, when a research on the loudness and pitch of tinnitus was performed with an acoustic stimulation of the pure tone type. Furthermore, the loudness balancing technique became widespread in 1938 to test the effect of tinnitus on hearing acuity when the contralateral ear is tested ${ }^{11}$.

In 1985, during a Symposium of CIBA-GEIGY (now Novartis), which is headquartered in London, efforts were concentrated on standardizing a protocol for the evaluation of tinnitus, including the measurement of pitch, loudness, minimum masking level, and residual inhibition?.

Previous literature reports that the psychoacoustic measures can be obtained through three different methods, i.e. the adjustment, limits, and adaptive methods $^{12}$. The adjustment method relies on the patient to adjust the stimulus (pulsatile tone) until the sound that is considered similar to his/her tinnitus is identified. In contrast, in the limits method, the patient is instructed to choose whether the stimulus presented (pulsating tones, ascending and descending, in increments of $1 / 6$ octave) is more bass or treble when compared to his/her tinnitus. Finally, the adaptive method, also referred to as the "Bracketing", requires the patient to determine whether the acoustic stimulus presented is brass or treble, but with increments of one octave. To guarantee reliable results, the tests are suggested to be repeated seven to nine times, regardless of the method used.

A debate regarding the type of stimulus to be utilized and the question of laterality (i.e. the presentation of the stimulus in an ipsilateral or contralateral way in relation to the ear where the tinnitus occurs) remains. In fact, while some authors use the contralateral measure as it is less confusing for the patient ${ }^{13}$, others prefer the ipsilateral measure to avoid the effects of diplacusis binauralis ${ }^{12}$.

Knowing how researchers and clinicians have conducted the audiological psychoacoustic measurements for the assessment of tinnitus will be of great importance to objectively validate this auditory symptom, which is subjective, by definition. Such measures might be important for counseling, followups, treatment-of-choice to be prescribed according to the suspected individualized diagnosis, and specifically for scientific research.

Although the literature categorizes the methods for conducting tests for psychoacoustic measurements, standards to obtain such parameters do not yet exist, in the field of audiology or in scientific research. Given the importance of the standardization of acuphenometry for the diagnosis and characterization of tinnitus, the purpose of this study was to review the national and international literature for methods of implementation of the psychoacoustic measures.

\section{METHODS}

The current integrative literature review was conducted on the articles present in specialized journals, both national and international in English 
and Portuguese, which are available in the following databases: US National Library of Medicine (PubMed/ Medline), Virtual Health Library - Latin American and Caribbean Literature on Health Sciences (BVS - LILACS) and Scientific Electronic Library Online (SCIELO).

To identify the articles relevant to our study, we considered terms related to the theme of "psychoacoustic measures in tinnitus", found in the Health Sciences Descriptors (DeCS), and the Medical Subject Headings (MeSH), as well as keywords relative to the topic, and combined them with the use of the Boolean operators $A N D$ and OR. The terms chosen for the search were used in an isolated and crossed manner (Figure 1). Finally, the filter "word" was used in all the searches.

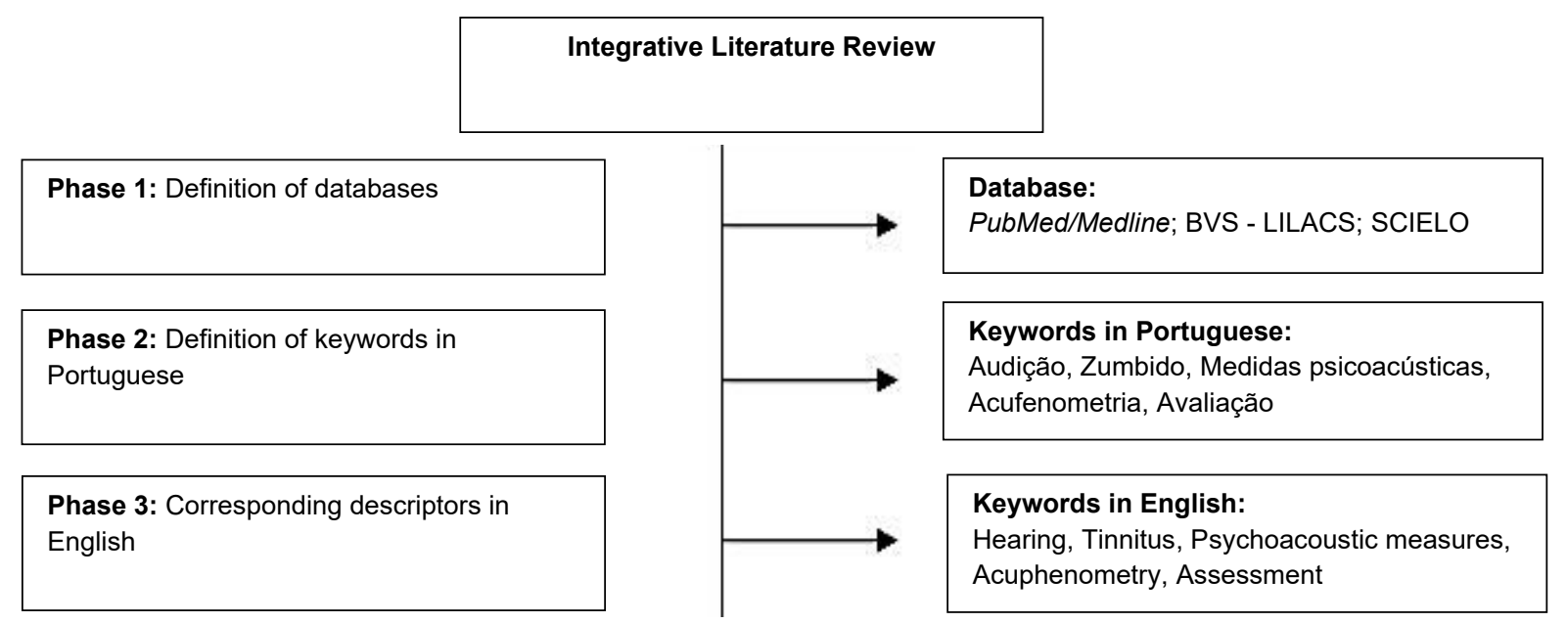

Figure 1. Determination of the databases as well as the keywords chosen for the integrative literature review

The main question underlying the present review was: "How are the psychoacoustic measures for the assessment of tinnitus recorded?". To obtain the answers to this question, a survey of the articles was conducted in the mentioned databases, specific for each database without limiting the search period (Figure 2).

Initially, both the inclusion and the exclusion of the articles were based on the information included in their titles and abstracts. However, when the resulting information was not conclusive, the articles were read fully to check if the following eligibility criteria were fulfilled: the utilization of psychoacoustic measures for the measurement of tinnitus, and the presence of a clear explanation of the method used, both in individuals within normal hearing thresholds and in those with hearing loss. Articles were excluded for the following reasons: they quoted the psychoacoustic measures used for the evaluation of tinnitus but did not present their description, they reviewed the literature and/ or methodology, they used a software for measuring the characteristics of tinnitus, they employed animals,

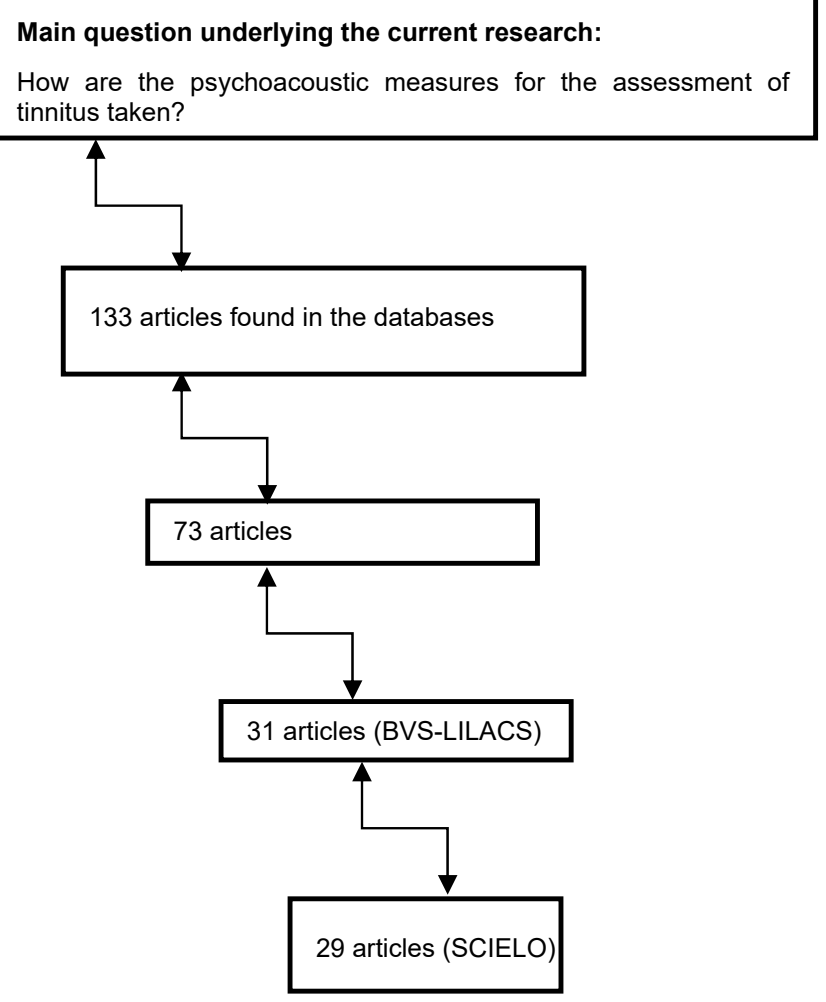

Figure 2. Selection process of the articles considered for the literature review 
and when only the summary and/or "abstract" were available.

The selected articles were analyzed, initially by reading the titles and abstracts, followed by a full reading of the articles that met the eligibility criteria. Each article was evaluated by one of the authors and, in case of doubt, a consensus was reached among all the authors regarding the inclusion of the article in the review. The publications which were found eligible for this review were organized into figures to extract the following information: year, author(s) of the research, purpose(s), sample characterization, and evaluation mode of the acuphenometry.

Finally, the articles that resulted from each crossed term (which was repeated in relation to the previous search and was related to the present study) were computed to organize the data.

\section{LITERATURE REVIEW}

As a result of the search performed in the Pubmed/ Medline, LILACS and SCIELO databases, 133 articles were found $(73,31$ and 29 , respectively). All the mentioned articles were identified in one or more databases. While reading the abstracts, duplicate articles (i.e. had previously been selected in other databases), those that did not meet the inclusion criteria and those for which the full text was not available during the period of the search were excluded.

Successively, the 133 abstracts, which were selected were read and the following were excluded: 30 due to the unavailability of the full text, 33 , which only mentioned the psychoacoustic measures that had been used for the evaluation of tinnitus, three that did not address the context of the "psychoacoustic measures and tinnitus", eight that only measured tinnitus by the use of questionnaires, six, as they were literature review studies, eight that reported studies measuring tinnitus with a software, one that only described the validation of an instrument for the evaluation of tinnitus, and two that were not available in both English and Portuguese. Finally, 29 articles were available in more than one database and were also excluded from the review.

After this detailed analysis, 12 articles that met the criteria for the current review were selected. Specifically, while seven were obtained from international journals, five were published in national journals. A summary of the articles published in the national journals relative to the use of psychoacoustic measures and their method of applicability for the assessment of tinnitus is shown in Figure 3.

In contrast, a summary of the articles published in the international journals is illustrated in Figure 4. 


\begin{tabular}{|c|c|c|c|}
\hline Year/ Authors & Objective(s) & \begin{tabular}{|l|}
$\begin{array}{l}\text { Characterization of the } \\
\text { sample }\end{array}$ \\
\end{tabular} & Assessment mode used in the acuphenometry \\
\hline $\begin{array}{l}\text { Rocha, } \\
\text { Mondelli, 2017 }\end{array}$ & $\begin{array}{l}\text { To determine the effectiveness } \\
\text { of the } S G \text { associated with the } \\
\text { counseling in the treatment } \\
\text { of } T \text { in individuals with and } \\
\text { without } H L \text { in relation to the } \\
\text { improvement of discomfort } \\
\text { and the HI. }\end{array}$ & $\begin{array}{l}30 \text { individuals of both genders, } \\
\text { distributed in: G1 - } 15 \\
\text { individuals with normal hearing } \\
\text { and an average of } 55.87 \text { years } \\
\text { of age, and G2 - } 15 \text { individuals } \\
\text { with HL of the sensorineural } \\
\text { type, bilateral and symmetric, } \\
\text { mild to moderate. }\end{array}$ & $\begin{array}{l}\text { Research on pitch: Investigated with either pure tone or NB noise according to } \\
\text { the characterization of the frequency of the T affecting the individual. The stimuli } \\
\text { were presented } 5 \mathrm{~dB} \text { more intense than the hearing thresholds at each frequency } \\
\text { researched. } \\
\text { Research on loudness: Research made at the frequency previously estimated, } \\
\text { increasing the intensity of the acoustic stimulus in steps of } 5 \mathrm{~dB} \text {, according } \\
\text { to the characterization of the intensity of the T affecting the individual. Such } \\
\text { psychoacoustic measures were again tested and the average of the values } \\
\text { obtained was calculated. When the suppression of T occurred (partial or total), } \\
\text { repetitions were not measured due to the absence of the symptom. }\end{array}$ \\
\hline $\begin{array}{l}\text { Benin et al., } \\
2016^{15} .\end{array}$ & $\begin{array}{l}\text { To analyze and compare T and } \\
\text { its impact on individuals with } \\
\text { and without HL, as well as its } \\
\text { characteristics relative to pitch, } \\
\text { loudness and location. }\end{array}$ & $\begin{array}{l}50 \text { individuals of both genders, } \\
29 \text { to } 69 \text { years old, divided into } \\
\text { normal hearing and } \mathrm{HL} \text { groups. }\end{array}$ & $\begin{array}{l}\text { Research on pitch: Additional } 10 \mathrm{dBNA} \text { were added relative to the auditory } \\
\text { threshold of each frequency, with the acoustic stimulation of the pure tone type } \\
\text { or noise, as per the description of the T characteristics. } \\
\text { Research on loudness: On the frequency chosen by the patient as similar to } \\
\text { his/her T, the stimulus was presented with an initial intensity of } 10 \mathrm{dBNA} \text { below } \\
\text { the threshold of the patient. Successively, the intensity was increased in steps } \\
\text { of } 2 \mathrm{dBNA} \text { and the patient was requested to signal when the intensity presented } \\
\text { was similar to his/her T. This intensity was recorded and subtracted from the } \\
\text { hearing threshold of the individual and this calculation determined the intensity } \\
\text { sensation of T in dBSL. }\end{array}$ \\
\hline $\begin{array}{l}\text { Suzuki, Suzuki, } \\
\text { Yonamine, } \\
\text { Onishi, Penido, } \\
2015^{16}\end{array}$ & \begin{tabular}{|l|} 
To demonstrate the \\
effectiveness of ST by \\
monitoring the patients \\
with different types of SG, \\
the relation of sequential \\
assessments using previously \\
established parameters (THI, \\
VAS, MML) and the need \\
for individual interventions \\
detailing the custom settings \\
of these SG in patients without \\
a response to previous \\
treatments for T. \\
\end{tabular} & $\begin{array}{l}10 \text { individuals, } 41 \text { to } 78 \\
\text { years old, complaining about } \\
\text { continuous chronic } T \text { for } \\
\text { more than one year, without } \\
\text { improvement when treated } \\
\text { with medicative therapies and } \\
\text { without specific treatment for T } \\
\text { at least for three months. }\end{array}$ & $\begin{array}{l}\text { The type of T they presented was taken into consideration and characterized in } \\
\text { acuphenometry: T of the "whistle" type equal to the pure tone, the "wheezing" } \\
\text { type similar to either the WN or NB, and the group with both types of T. The } \\
\text { same criteria for the assessments and adjustments were followed in all groups. } \\
\text { With regards to the MML, the research focused on determining which was the } \\
\text { lower masking intensity of the T in an ascending way, using noise bilaterally } \\
\text { (first WN followed by NB at the frequency of the T and then NB at } 500 \mathrm{~Hz} \text { ). }\end{array}$ \\
\hline $\begin{array}{l}\text { Urnau, Tochetto, } \\
2011^{17 .}\end{array}$ & $\begin{array}{l}\text { To analyze the characteristics } \\
\text { of T and hyperacusis in } \\
\text { individuals with normal } \\
\text { hearing, as well as the } \\
\text { associated complaint of T and } \\
\text { hyperacusis }\end{array}$ & $\begin{array}{l}25 \text { individuals with normal } \\
\text { hearing of both genders, } 21 \text { to } \\
70 \text { years old. }\end{array}$ & $\begin{array}{l}\text { Only the T pitch research was conducted. Either a pure tone stimulus, a NB or a } \\
\text { WN was presented in the contralateral ear in relation to the T. In cases of bilateral } \\
\text { T, the stimulus was presented in the contralateral ear to the more intense T. } \\
\text { The stimulus was provided at an intensity of } 15 \mathrm{dBSL} \text { in the frequencies of } 250 \\
\text { to } 8000 \mathrm{~Hz} \text { until the individual could identify the frequency of his/her tinnitus. } \\
\text { To determine the compatibility between the pitch reported by the patient and } \\
\text { the one determined by acuphenometry, the NB and pure tone stimuli above } 1 \\
\text { KHz were classified as treble, while those below } 1 \mathrm{KHz} \text { were defined as bass. } \\
\text { Given that the WN covers an extensive range of frequencies, it was considered } \\
\text { compatible with any pitch mentioned, either treble or bass. }\end{array}$ \\
\hline $\begin{array}{l}\text { Moura, lório, } \\
\text { Azevedo, 2004 }\end{array}$ & $\begin{array}{l}\text { To check the efficiency of } \\
\text { the adaptation to PSAPs in } \\
\text { the reduction or elimination } \\
\text { of T in patients with HL. To } \\
\text { characterize the T. To determine } \\
\text { other factors that might } \\
\text { interfere with the improvement } \\
\text { of T, such as length of usage } \\
\text { and characteristics of the } \\
\text { PSAP. }\end{array}$ & $\begin{array}{l}47 \text { individuals of both genders, } \\
33 \text { to } 88 \text { years old, with } \mathrm{HL} \text { of } \\
\text { the sensorineural type, mild to } \\
\text { profound, unilateral or bilateral, } \\
\text { with T and with a medical } \\
\text { indication to adaptation to } \\
\text { PSAPs. }\end{array}$ & $\begin{array}{l}\text { Research on pitch: Either pure tone type stimuli or NB (depending on the type } \\
\text { of T) were presented to the contralateral ear in relation to the T, at } 15 \mathrm{dBSL} \text {, at } \\
\text { various frequencies, until the individual could identify the frequency of his/her T. } \\
\text { Research on loudness: From the established frequency, the intensity of the } \\
\text { stimulus was decreased by } 5 \mathrm{~dB} \text { each time, until the individual identified the } \\
\text { intensity closest to his/her T. }\end{array}$ \\
\hline
\end{tabular}

Caption: $\mathrm{THI}=$ Tinnitus Handicap Inventory; $\mathrm{SG}=$ sound generator; pitch = sensation of sound frequency loudness = sensation of sound intensity; $\mathrm{MML}=$ minimum masking level; $\mathrm{PSAP}=$ personal sound amplification product; $\mathrm{HL}=$ hearing loss; $\mathrm{dBSL}=$ decibels sensation level; $\mathrm{ST}=$ sound therapy; $\mathrm{VAS}=$ visual analogue scale; $\mathrm{T}=$ tinnitus; $\mathrm{HI}=$ hearing impairment; $\mathrm{NB}=$ Narrow Band; $\mathrm{WN}=$ White Noise; $\mathrm{Hz}=$ Hertz.

Figure 3. Synthesis of the national articles selected and analyzed for the present review $(n=5)$ 


\begin{tabular}{|c|c|c|c|}
\hline Authors/ Year & Objective(s) & Total of subjects & Assessment mode used in the acuphenometry \\
\hline \begin{tabular}{l|} 
Ibraheem, \\
Hassaan, $2017^{19}$
\end{tabular} & $\begin{array}{l}\text { To examine the relationship } \\
\text { between the psychoacoustic } \\
\text { measures of T and the } \\
\text { auditory temporal resolution } \\
\text { in individuals with normal } \\
\text { hearing. }\end{array}$ & $\begin{array}{l}30 \text { individuals of both genders, } \\
20 \text { to } 45 \text { years old, distributed } \\
\text { as: } 15 \text { individuals with normal } \\
\text { hearing and without complaints } \\
\text { of T and } 15 \text { with normal } \\
\text { hearing with complaints of T. }\end{array}$ & $\begin{array}{l}\text { Research on pitch: It was conducted in the ear without T when T was unilateral } \\
\text { and in the better ear when it was bilateral. A stimulus was presented starting } \\
\text { from } 1,000 \mathrm{~Hz} \text { at } 5-10 \mathrm{dBSL} \text {, followed by increases and decreases of the } \\
\text { octave, according to the description of the participants. Research on loudness: } \\
\text { The frequency determined during the research of the tinnitus' pitch was used, at } \\
\text { a level below the threshold and the intensity was increased in steps of } 1 \mathrm{~dB} \text { until } \\
\text { a correspondence to intensity was identified. The correspondence of loudness } \\
\text { was expressed in dBSL. }\end{array}$ \\
\hline \begin{tabular}{l|} 
Seimetz, \\
Teixeira, Rosito, \\
Flores, Pappen, \\
Dall'igna, 2016 20
\end{tabular} & $\begin{array}{l}\text { To analyze the existence of an } \\
\text { association between hearing } \\
\text { thresholds, the tone and the } \\
\text { intensity of T in patients with } \\
\text { presbyacusis, according to } \\
\text { gender. }\end{array}$ & \begin{tabular}{|l|}
49 individuals with \\
presbyacusis diagnosis and \\
presence of unilateral or \\
bilateral tinnitus, both genders, \\
average age of 69.57 years.
\end{tabular} & $\begin{array}{l}\text { Research on pitch: The research on pitch was conducted using all the } \\
\text { frequencies, adding } 10 \mathrm{dBNA} \text { at the hearing threshold for each frequency and } \\
\text { either a pure tone or noise, depending on the characteristics of T. } \\
\text { Research on loudness: It was performed according to the frequency found in } \\
\text { the research on pitch, with an intensity of } 10 \mathrm{dBNA} \text { below the hearing threshold, } \\
\text { increased in steps of } 2 \mathrm{~dB} \text {, until the intensity presented was similar to that of T. } \\
\text { The sensation level was calculated by subtracting this intensity from the hearing } \\
\text { threshold frequency. }\end{array}$ \\
\hline $\begin{array}{l}\text { Heyning et al. } \\
2014 . .^{21}\end{array}$ & $\begin{array}{l}\text { To evaluate the effectiveness } \\
\text { and safety of the intratympanic } \\
\text { procedure AM-101 in patients } \\
\text { with acute internal persistent T } \\
\text { after acoustic trauma. }\end{array}$ & \begin{tabular}{|l|}
248 individuals aged between \\
16 and 65 years, with a \\
diagnosis of either $\mathrm{HL}$ of the \\
idiopathic sensorineural type or \\
chronic otitis media.
\end{tabular} & $\begin{array}{l}\text { The MML is a descending method, started at } 70 \mathrm{dBNA} \text { with pulsatile noise. } \\
\text { Specifically, the intermediate point between the audible and the inaudible is the } \\
\text { MML. } \\
\text { Correspondence to the loudness: A tone of } 1 \mathrm{KHz} \text { pulsatile was presented at an } \\
\text { intensity of } 15 \mathrm{~dB} \text { above the threshold. The participants were asked whether the } \\
\text { tone presented was stronger or weaker than the intensity of T. The intensity was } \\
\text { adjusted in steps of } 1 \mathrm{~dB} \text { until the exact value was determined. } \\
\text { These procedures were performed three times and the result was the average } \\
\text { of these values, as long as the value was within a range of } 5 \mathrm{~dB} \text {. In the case of } \\
\text { extreme values, a new measurement was performed. }\end{array}$ \\
\hline $\begin{array}{l}\text { Santos, Bento, } \\
\text { Medeiros, } \\
\text { Oiticcica, Silva, } \\
\text { Penteado, 2014² }\end{array}$ & $\begin{array}{l}\text { To determine whether the } \\
\text { combined use of PSAPS and } \\
\text { SG is more effective than } \\
\text { the use of PSAP alone in } \\
\text { reducing the discomfort of T } \\
\text { in patients with T and bilateral } \\
\text { symmetrical sensorineural HL, } \\
\text { mild to moderate, using a new } \\
\text { PSAP with an integrated SG } \\
\text { developed by the Department } \\
\text { of Otolaryngology of the XXXX. }\end{array}$ & $\begin{array}{l}49 \text { individuals of both genders, } \\
\text { aged between } 21 \text { and } 72.1 \\
\text { years. All of them showed HL } \\
\text { of the bilateral symmetrical } \\
\text { sensorineural type, mild to } \\
\text { moderate, with complaints } \\
\text { of constant T for, at least, six } \\
\text { months and without previous } \\
\text { experience with either PSAP or } \\
\text { other types of ST. }\end{array}$ & $\begin{array}{l}\text { Research on pitch: The participants were instructed to relate the most } \\
\text { uncomfortable frequency with the perception of T. In the cases of asymmetrical } \\
\text { T, the contralateral ear was used as the reference, whereas the RE was used as } \\
\text { the reference in the case of symmetric T in either both ears or in the center of } \\
\text { the head. A pure tone stimulus type was used, except for those cases where the } \\
\text { patient described the T as treble. The stimulus was presented at a level } 5-10 \mathrm{~dB} \\
\text { above the hearing threshold of each frequency, starting at } 1,000 \mathrm{~Hz} \text { and was } \\
\text { either increased or decreased according to the instructions of the individual. } \\
\text { Research on loudness: The ear and frequency used in the research of the pitch } \\
\text { were. The stimulus used for the research of the loudness was initially presented } \\
\text { below the hearing threshold and increased in steps of } 2 \mathrm{~dB} \text { until the participant } \\
\text { acknowledged an equivalence of the intensity to the T. With regards to the MML } \\
\text { test, the WN stimulus type was presented below the hearing threshold and was } \\
\text { increased in steps of } 5 \mathrm{~dB} \text { until the participant indicated that the T was either } \\
\text { masked, partially masked or unchanged. }\end{array}$ \\
\hline $\begin{array}{l}\text { Ooms, Meganck, } \\
\text { Vanheule, } \\
\text { Vinck, Watelet, } \\
\text { Dhooge, } 2011^{23}\end{array}$ & $\begin{array}{l}\text { To investigate whether the } \\
\text { severity of } T \text { is a problem } \\
\text { related to depression. }\end{array}$ & \begin{tabular}{|l|}
136 individuals with an \\
average age of 49.11 years \\
and complaints of T. All \\
participants were medicated \\
with antidepressant drugs \\
and 12 were receiving \\
psychological counseling for T.
\end{tabular} & $\begin{array}{l}\text { Concordance of the pitch and loudness: This was an alternative procedure } \\
\text { related to forced-choice pairs. Two tones were presented to the participants, } \\
\text { who were instructed to choose which of them was more similar to their T, both } \\
\text { in terms of frequency and intensity. Subsequently, for the concordance of the } \\
\text { pitch, an octave confusion test was performed, in which participants should } \\
\text { identify a tone as similar to their T. With regards to the concordance of the } \\
\text { loudness, the sound stimulus was presented in the frequency of T chosen by } \\
\text { the participant, at a level of intensity below the threshold, and the intensity was } \\
\text { increased until the patient signaled an existence of concordance. }\end{array}$ \\
\hline $\begin{array}{l}\text { Seidman et al., } \\
2008^{24}\end{array}$ & $\begin{array}{l}\text { To check the effect of electrical } \\
\text { stimulation on the auditory } \\
\text { cortex of patients with tinnitus. }\end{array}$ & $\begin{array}{l}\text { Two individuals aged between } \\
40 \text { and } 50 \text { years with severe } \\
\text { debilitating tinnitus. }\end{array}$ & $\begin{array}{l}\text { Concordance of pitch: Pure tone stimuli were presented, starting at } 1,000 \mathrm{~Hz} \text {, } \\
\text { until the approximate pitch was chosen. Once the estimate was determined, } \\
\text { the alternative procedure of forced-choice pairs was performed to determine } \\
\text { the pitch. Tones distant of one octave to the chosen one were presented as a } \\
\text { choice to discard the confusion octave. Seven choices of pitch were made in an } \\
\text { attempt to increase reliability. Ipsilateral measures were conducted to ensure the } \\
\text { exclusion of diplacusis binauralis in the concordance. } \\
\text { Concordance of loudness: They were performed using the frequency } \\
\text { determined in the pitch concordance. A continuous tone was presented below } \\
\text { the threshold, to the contralateral ear, and increased by } 1 \mathrm{~dB} \text { every two seconds } \\
\text { until the patient indicated that the tone was equivalent in loudness to T. Three } \\
\text { concordances were obtained, and the final tally was recorded in } \mathrm{dBSL} \text {. To obtain } \\
\text { the MML, the WN was ipsilaterally presented at the intensity of } 10 \mathrm{~dB} \text { below the } \\
\text { AL and was increased until the patient could hear it. The level of masking was } \\
\text { then lowered and increased until the patient indicated that the WN masked the T. }\end{array}$ \\
\hline
\end{tabular}




\begin{tabular}{|l|l|l|l|}
\hline Authors/ Year & Objective(s) & Total of subjects & Assessment mode used in the acuphenometry \\
\hline $\begin{array}{l}\text { Kroner-Herwig et } \\
\text { al., 1995 }\end{array}$ & $\begin{array}{l}\text { To differentiate the } \\
\text { effectiveness of a non-specific } \\
\text { program (yoga) versus a } \\
\text { specific program of target } \\
\text { problem (training on T) } \\
\text { and examine the pattern of } \\
\text { effectiveness using a wide } \\
\text { range of outcome variables } \\
\text { (psychoacoustic/daily/ } \\
\text { psychometric/global self- } \\
\text { description). }\end{array}$ & $\begin{array}{l}43 \text { individuals with an average } \\
\text { age of 48 years and complaint } \\
\text { of chronic T, assessed } \\
\text { immediately after the therapy } \\
\text { and during the 3-month follow- } \\
\text { up. }\end{array}$ & $\begin{array}{l}\text { The level of sensation of T was measured by asking the patient to match the } \\
\text { level of intensity and the frequency of a sound similar to his/her Z. The sound } \\
\text { level (dB) was related to the auditory thresholds. The level of T masking was } \\
\text { determined for both ears. A frequency spectrum between 125 Hz and 10,000 } \\
\text { Hz was presented to each ear. A single parameter of masking level of the T } \\
\text { was used for each individual, calculating the median of all levels of masking } \\
\text { recorded. }\end{array}$ \\
\hline
\end{tabular}

Caption: $\mathrm{MML}=$ Minimum masking level; $P S A P=$ personal sound amplification product; $r \mathrm{TMS}=$ repetitive transcranial magnetic stimulation; $\mathrm{dBNA}=$ decibels auditory level. $\mathrm{KHz}=$ kilohertz; $\mathrm{SG}=$ sound generator; $\mathrm{ST}=$ sound therapy; $\mathrm{RE}=$ right ear; $\mathrm{Z}=$ tinnitus; $\mathrm{MML}=$ minimum masking level; $\mathrm{AL}=$ auditory level; $\mathrm{CG}=\mathrm{control}$ group; $\mathrm{EG}=$ experimental group; $\mathrm{dBSL}=$ decibels sensation level; $\mathrm{HL}=$ hearing loss; $\mathrm{dB}=$ decibels; $\mathrm{WN}=$ White Noise; $\mathrm{ORL}=$ Otorhinolaryngology

Figure 4. Synthesis of the national articles selected and analyzed for the present review $(n=7)$

This study presents an overview of the research developed under a national and international scope, using psychoacoustic measures to assess and characterize tinnitus, in both individuals with normal hearing and hearing loss. In addition, we have also described the use of these psychoacoustic measures in guiding researchers and professionals in the evaluation of patients with tinnitus.

Based on the studies analyzed, we could infer an absence of consensus on the standardization of the measurement of tinnitus while performing acuphenometry, which may influence the results of the assessment. The divergent results may be caused by extrinsic (how the guidance prior to assessment is made) and intrinsic factors (variation of the loudness intensity in the research). However, most of the studies describe the correspondence between pitch and loudness, as well as the type and intensity of the stimulus presented, according to the severity of the patient's tinnitus.

With regards to the national literature, pure tone, white noise and narrow band ${ }^{16,17}$ stimuli were used to determine both the pitch and loudness of tinnitus. The intensity of both pitch and loudness were found to vary between $5^{14}, 10^{15}$ and $15 \mathrm{dBNS}{ }^{17,18}$.

Furthermore, the researchers of two studies measured and characterized tinnitus either in the contralateral ear or in the ear in which the tinnitus was not prevalent ${ }^{17,18}$.

In the international literature, pure tone $\mathrm{e}^{20,22}$, noise ${ }^{20}$ and pulsatile ${ }^{21}$ stimuli were used to determine the pitch and loudness of tinnitus.

Moreover, we observed the applicability of the Minimum Masking Level (MML) in the characterization and the measurement of tinnitus on the different protocols which were found to be used. The MML is a psychoacoustic estimate of the lowest level of broadband noise to minimally mask the tinnitus in the patient ${ }^{26}$.

Two studies (one national ${ }^{16}$ and one international ${ }^{21}$ ) reported that the measuring the MML of tinnitus could be used as a complementary method to the identification of loudness in acuphenometry. However, the remaining studies only used the correspondence between the pitch and the loudness to perform the acuphenometry, showing great heterogeneity in their protocols.

\section{CONCLUSION}

Given the grouping of several protocols for tinnitus evaluation, which were determined following an integrative literature review, a great heterogeneity in the methods used to perform psychoacoustic measurements for tinnitus assessment for both clinical and scientific purposes was noted.

\section{REFERENCES}

1. Husain FT, Medina RE, Davis CW, Szymko-Bennett Y, Simonyan K, Pajor NM et al. Neuroanatomical changes due to hearing loss and chronic tinnitus: A combined VBM and DTI study. Brain Res. 2011;1369:74-88.

2. Zeman $F$, Koller $M$, Langguth $B$, Landgrebe $M$. Which tinnitus-related aspects are relevant for quality of life and depression: results from a large international multicentre sample. Health Qual Life Outcomes. 2014;12(7):1-10.

3. Hesse G, Schaaf $H$, Laubert A. Specific findings in distortion product otoacustic emissions and 
growth functions with chronic tinnitus. Int Tinnitus J. 2005;11(1):6-13.

4. Moura LOS, lório MCM, Azevedo MF. A eficácia da adaptação de prótese auditiva na redução ou eliminação do zumbido. Braz J Otorhinolaryngol. 2004;70(5):624-31.

5. Steves CC, Brandão FN, Siqueira CGA, Carvalho SAS. Audição, zumbido e qualidade de vida: um estudo piloto. Rev. CEFAC. 2012;14(5):836-43.

6. Newman CW, Jacobson GP, Spitzer JB. Development of the Tinnitus Handicap Inventory. Arch Otolaryngol Head Neck Surg. 1996;122(2):143-8.

7. Azevedo AA, Oliveira PM, Siqueira AG, Figueiredo RR. Análise crítica dos métodos de mensuração do zumbido. Braz J Otorhinolaryngol. 2007;73(3):418-23.

8. Menezes P, Santos Filha VAV. Acufenometria: o resgate de um instrumento de avaliação do zumbido e sua correlação com perdas auditiva sensoriais. Fonoaudiologia Brasil. 2005;3(1):1-4.

9. Henry JA. Measurement of tinnitus. Otol Neurotol. 2016;37(8):e276-e285.

10. Wegel RL. A study of tinnitus. Arch Otolaryngol Head Neck Surg. 1931;14(2):158-65.

11. Fowler EP. The use of threshold and louder sounds in clinical diagnosis and the prescribing of hearing aids. New methods for accurately determining the threshold for bone conduction and for measuring tinnitus and its effects on obstructive and neural deafness. Trans Am Otol Soc. 1938;28:154-71.

12. Tyler RS, Conrad-Armes D. Tinnitus pitch: a comparison of three measurement methods. $\mathrm{Br} \mathrm{J}$ Audiol. 1983;17(2):101-7.

13. Vernon J, Johnson R, Schleunin A. The characteristic and natural history of tinnitus in Meniere's disease. Otolaryngol Clin North Am. 1980a;13(4):611-9.

14. Rocha AV, Mondelli MFCG. Sound generator associated with the counseling in the treatment of tinnitus: evaluation of effectiveness. Braz J Otorhinolaryngol. 2017;83(3):249-55.

15. Benin L, Teixeira AR, Lessa AH, Rosito LPS, Walbrohel I, Picinini $T$ et al. Zumbido crônico: estudo em indivíduos com e sem perda auditiva. ConScientiae Saúde. 2016;15(4):657-64.
16. Suzuki FAB, Suzuki FA, Yonamine FK, Onishia ET, Penidoa NO. Effectiveness of sound therapy in patients with tinnitus resistant to previous treatments: importance of adjustments. Braz J Otorhinolaryngol. 2016;82(3):297-303.

17. Urnau D, Tochetto TM. Características do zumbido e da hiperacusia em indivíduos normo-ouvintes. Arq Int Otorrinolaringol. 2011;15(4):468-74.

18. Moura LOS, lório MCM, Azevedo MF. A eficácia da adaptação de prótese auditiva na redução ou eliminação do zumbido. Braz J Otorhinolaryngol. 2004;70(5):624-31.

19. Ibraheem OA, Hassaan MR. Psychoacoustic characteristics of tinnitus versus temporal resolution in subjects with normal hearing sensitivity. Int Arch Otorhinolaryngol. 2017;21(2):144-50.

20. Seimetz BM, Teixeira AR, Rosito LPS, Flores LS, Pappen $\mathrm{CH}$, Dall'igna $\mathrm{C}$. Pitch and Loudness Tinnitus in Individuals with Presbycusis. Int Arch Otorhinolaryngol. 2016;20(4):321-6.

21. Van de Heyning $P$, Muehlmeier G, Cox T, Lisowska $\mathrm{G}$, Maier $\mathrm{H}$, Morawski $\mathrm{K}$ et al. Efficacy and safety of AM-101 in the treatment of acute inner ear tinnitus va double-blind, randomized, placebo-controlled phase ii study. Otol Neurotol. 2014;35(4):589-97.

22. Santos GM, Bento RF, Medeiros IRT, Oiticcica $J$, Silva EC, Penteado S. The influence of sound generator associated with conventional amplification for tinnitus control: randomized blind clinical Trial. Trends Hear. 2014;18:1-9.

23. Ooms E, Meganck R, Vanheule S, Vinck B, Watelet JB, Dhooge I. Tinnitus severity and the relation to depressive symptoms: a critical study. Otol Neurotol. 2011;145(2):276-81.

24. Seidman MD, Ridder D, Elisevich K, Bowyer SM, Darrat I, Dria $\mathrm{J}$ et al. Direct electrical stimulation of Heschl's Gyrus for tinnitus treatment. Laryngoscope. 2008;118:491-500.

25. Kroner-Herwig B, Hebing G, Van Rijn-Kalkmann U, Frenzel A, Schilkowsky G, Esser G. The management of chronic tinnitus-comparison of a cognitive-behavioural group training with yoga. $\mathrm{J}$ Psychosom Res. 1995;39(2):153-65.

26. Henry JA, Meikle MB. Psychoacoustic measures of tinnitus. J Am Acad Audiol. 2000;11:138-55. 